This item was submitted to Loughborough's Research Repository by the author.

Items in Figshare are protected by copyright, with all rights reserved, unless otherwise indicated.

\title{
An exploration of European road users' safety attitudes towards speeding
}

PLEASE CITE THE PUBLISHED VERSION

https://doi.org/10.1080/19439962.2019.1650144

PUBLISHER

Taylor and Francis

\section{VERSION}

AM (Accepted Manuscript)

\section{PUBLISHER STATEMENT}

This is an Accepted Manuscript of an article published by Taylor \& Francis in Journal of Transportation Safety and Security on 14 Aug 2019, available online: https://doi.org/10.1080/19439962.2019.1650144

\section{LICENCE}

CC BY-NC-ND 4.0

\section{REPOSITORY RECORD}

Laiou, Alexandra, Athanasios Theofilatos, George Yannis, Uta meesmann, and Katrien Torfs. 2019. "An Exploration of European Road Users' Safety Attitudes Towards Speeding”. Loughborough University. https://hdl.handle.net/2134/9948596.v1. 


\title{
An exploration of European road users' safety attitudes towards speeding
}

\author{
Alexandra Laiou ${ }^{1 *}$, Athanasios Theofilatos ${ }^{1}$, George Yannis ${ }^{1}$, \\ Uta Meesmann², Katrien Torfs ${ }^{2}$ \\ ${ }^{1}$ Department of Transportation Planning and Engineering, National Technical University of Athens, \\ Zografou Campus, Iroon Polytechniou 5, 15773, Athens, Greece \\ ${ }^{2}$ VIAS Institute, Haachtsesteenweg 1405, 1130 Brussels, Belgium
}

\begin{abstract}
The objective of this paper is to describe the attitudes and opinions of Europeans on speeding, and compare them amongst countries and based on demographic characteristics as well as to provide a number of recommendations to be used in the effort to reduce speeding and improve road safety. The analysed data were collected within the ESRA project, a joint initiative of research organisations in 17 European countries aiming at collecting comparable (inter)national data on road users' opinions, attitudes and behaviour with respect to road traffic risks. Data from more than 17,000 road users were collected. The speeding aspects analysed concern acceptability of unsafe traffic behaviour related to speeding, self-declared behaviour in traffic, attitudes towards unsafe traffic behaviour, support for road safety policy measures and reported police checks and perceived likelihood of getting caught for speeding. All reported attitudes depend on participants' gender and age. The majority of people who accept driving over the speed limit do not believe that speed limits are set at acceptable levels. The ESRA results are also compared to those of previous similar studies. Finally, key recommendations concerning speeding were formulated, addressed to stakeholders at three different levels namely European level, national/regional level and particular stakeholders.
\end{abstract}

\footnotetext{
${ }^{*}$ Corresponding author.

E-mail address: alaiou@central.ntua.gr (A.Laiou)
} 


\section{Keywords}

Road safety; Speeding; Attitudes; Europe; ESRA

\section{Introduction}

Speeding is the number one road safety problem in many OECD/ECMT countries (OECD/ECMT, 2006). This is reflected in the current Road Safety Programme 2011-2020 of the European Commission, within which speed related issues are included in four out of the seven strategic objectives of the Programme (i.e. improved safety measures for vehicles, boost smart technology, better enforcement, a new focus on motorcyclists) (European Commission, 2010; Laiou, Yannis \& Možina, 2015).

Speed is a central issue in road safety, and one of the basic risk factors in traffic (ETSC, 2010; OECD/ECMT, 2006; Wegman \& Aarts, 2006). In 2010, the European Transport Safety Council (ETSC) has included speed among the three main risk factors on the roads, the others being alcohol and non-use of seat belts. Excessive and inappropriate speed has been recognised as the number one road safety problem. Speeding was found to be a primary factor in about one third of fatal accidents and an aggravating factor in all accidents (ETSC, 2010).

Speed has a direct influence on crash occurrence and severity. With higher driving speeds, the number of crashes and the crash severity increase disproportionally. With lower speeds the number of crashes and the crash severity decrease (OECD/ITF, 2018).

There are many factors that affect the exact relation between speed and the risk of a road accident; however, in a general sense, if the driven speeds on a road become higher, the road accident rate will also increase. The road accident rate is also higher for an individual vehicle 
that drives at higher speed than the other traffic on that road. The reasons for this accident increase rest on both human factors and vehicle dynamics: on one hand, high speeds reduce the available time for drivers to process information, to decide whether or not to react and to execute a reaction; on the other hand, braking distance is increased at high speeds, and it is more common to lose control of a vehicle (e.g. in a sharp curve) at higher speeds (SWOV, 2012; European Commission, 2015).

An attempt to quantify the relationship between speed and accident risk has been made in several studies (Elvik, 2009; Elvik et al., 2004; Nilsson, 1981; 2004) and it has been suggested that it is a power function; on a particular road with increasing speed, the absolute speed gets higher and the accident risk increases more. More recently, it was found that the relationship between speed and road safety depends not only on the relative change in speed but also on the initial speed (Elvik, 2013).

A different aspect of the relationship between speed and road safety is the impact of speed in the severity of a road accident (SWOV, 2012). The higher the collision speed, the more serious the consequences in terms of injury and material damage. According to the latest reports $(\mathrm{OECD} / \mathrm{ITF}, 2018)$ the effect of a given relative change in speed on the number and severity of crashes is larger when initial speed is higher. In addition to collision speed, the mass difference between vehicles and the vulnerability of the vehicles/road users who are involved are also important factors for injury severity; thus, it is clear that speed has a greater effect on the severity of accidents involving pedestrians, cyclists and powered two-wheelers.

The reasons for speeding are diverse and may relate to temporary motives (e.g. being in a hurry), to more permanent personality characteristics (e.g. risk taking), to human perceptual skills and limitations, as well as to characteristics of the road, the road environment and the vehicle (European Commission, 2018). Studies of self-reported speeding in Europe (SARTRE4, 2012), Australia (Hatfield \& Job, 2006; Stephens, Nieuwesteeg, Page-Smith \& 
Fitzharris, 2017), the United States of America (Schroeder, Kostyniuk \&Mack, 2013) and in the United Kingdom (Lawton, Parker \&Stradling, 1997) suggest that speeding is more likely amongst respondents who are male (Hatfield \& Job, 2006; SARTRE4, 2012; Schroeder et al, 2013; Stephens at al, 2017), younger (Lawton et al, 1997; Hatfield \& Job, 2006; SARTRE4, 2012; Schroeder et al, 2013; Stephens at al, 2017), more educated (Hatfield \& Job, 2006), with higher household incomes(Schroeder et al, 2013) single (Hatfield \& Job, 2006), and who have held their license for a shorter period (Hatfield \& Job, 2006). When compared to compliant drivers, non-compliers perceive less risk of a serious road accident, report greater likelihood of exceeding the speed limit when they believe they would not be detected, and report a higher level of social acceptability of speeding (Lawton et al, 1997; Schroeder et al, 2013; Stephens at al, 2017).

In relation to road and environment characteristics, self-reported speeding has been found to be less likely under poor conditions (wet, night, winding road) and near schools. On the contrary, it is more likely in situations where it has clear benefits and is perceived as unlikely to result in having an accident or being booked (Hatfield \& Job, 2006).

The acceptability of proposed speeding countermeasures varies among driver types, but overall, drivers are more receptive to countermeasures if they do not include specific penalties. Overall, most drivers make judgements about the type of road on which they are driving and the degree of speeding that is acceptable, and that their intentions to speed vary accordingly (Lawton et al, 1997; Schroeder et al, 2013).

Fleiter \& Watson (2006) examined the speed paradox of the misalignment between driver attitudes and speeding behaviour meaning that drivers may subscribe to one belief (that speeding is wrong or dangerous) yet regularly exceed the posted speed limit. It was found that two thirds of drivers in Australia agree that exceeding the limit is not worth the risks nor is it okay to exceed the posted limit. Despite this, more than half (58.4\%) of them reported a 
preference to exceed the $100 \mathrm{~km} /$ hour speed limit, with one third preferring to do so by 10 to $20 \mathrm{~km} /$ hour. Further, mean preferred driving speeds on both urban and open roads suggest a perceived enforcement tolerance of $10 \%$, suggesting that posted limits have limited direct influence on speed choice.

In order to solve the problem of speeding, an integrated set of countermeasures is necessary. This approach increases the effectiveness of each individual measure (OECD/ECMT, 2006). The most appropriate combination of measures will differ with circumstances. In principle, effective speed management requires an integrated, systematic and stepwise approach. Within the current system of largely fixed speed limits, the following steps are important: setting speed limits, providing information about the speed limit in force, implementing road engineering measures, enforcing speed limit and ensuring driver education and publicity.

Currently, speed limits vary across the EU Member States and depend on the type of road (e.g. motorways, rural roads, residential areas), on the type of vehicle (e.g. Heavy Goods Vehicles, buses/coaches) on the weather (e.g. rain, snow, fog), and on traffic conditions (to avoid congestion). In addition, several different types of speed enforcement methods are implemented in the various countries. These facts imply that there may be significant differences in speed management among the Member States that should be addressed at a European level through the implementation of relevant EU Directives and other legislative procedures. Still, speed management strategies in different countries may follow common principles but it is necessary that they are adapted to the actual conditions and driver characteristics in the area where they will be implemented.

In the framework of an integrated speed management strategy, there are several stakeholders with specific roles and responsibilities. Apart from public authorities at national, regional and local level (i.e. Ministry of Infrastructure, Ministry of Transport, Prefecture 
Authorities, National and Municipal Public Work Authorities, Traffic Police etc.) other stakeholders such as non-governmental organisations, private road network operators, research organisations and vehicle manufacturers may have significant role in speed management. Therefore, specific guidelines and directions addressed to the different stakeholders on how to tackle speeding based on their particular roles and responsibilities are necessary.

Based on the above, this paper aims at describing the attitudes and opinions of road users in 17 European countries on speeding, and comparing it amongst countries as well as with regards to demographic characteristics (e.g. gender and age). Moreover, the paper aims at providing a number of recommendations addressed to road safety stakeholders at different levels to be exploited in their effort to reduce speeding and improve road safety.

The analysed data concern the first E-Survey on Road Users' Attitudes (ESRA) conducted in 2015 (Torfs, Meesmann, Van den Berghe \& Trotta, 2016). Some of the ESRA2015 questions have already been used in the SARTRE4 survey (Cestac \& Delhomme, 2012), allowing for an assessment of the development in the perspective of previous years. Moreover slightly different or new questions are introduced in ESRA2015 and can be considered as a first benchmark for future comparison and monitoring of road safety attitudes of European drivers.

\section{Methodology}

ESRA2015 is a joint initiative of research organisations and road safety institutes in 17 European countries aiming at collecting comparable (inter)national data on road users' opinions, attitudes and behaviour with respect to road traffic risks. The project was funded by the partners' own resources. 
The ESRA2015 survey was conducted online, using representative samples (at least $\mathrm{N}=1,000$ ) of the national adult populations in 17 European countries (Austria, Belgium, Denmark, Finland, France, Germany, Greece, Ireland, Italy, Poland, Portugal, Slovenia, Spain, Sweden, Switzerland, the Netherlands, United Kingdom). In total, data from more than 17,000 road users were collected. A common questionnaire was developed and translated into 20 different country-language versions. The questions covered a range of subjects, including the attitudes towards unsafe traffic behaviour, self-declared (unsafe) behaviour in traffic, and support for road safety policy measures - overall more than 222 variables. The ESRA2015 questionnaire was inspired by the previous European project, SARTRE, and also includes some questions of the AAAFTS-survey (USA) 'Traffic Safety Culture Index', which enables tentative comparisons with these projects. Data collection took place simultaneously in all countries in June/July 2015. The uniform sampling procedure and methodology was guaranteed through the coordination of the field work in the 17 countries by only one polling agency.

ESRA2015 was undertaken by seven institutes - VIAS Institute (BE), the Kuratorium für Verkehrssicherheit - KFV (AT), the National Technical University of Athens - NTUA (EL), the Centro di Ricerca per il Trasporto e la Logistica, 'Sapienza' Università di Roma - CTL (IT), the Instytutu Transportu Samochodowego - ITS (PL), Prevenção Rodoviária Portuguesa - PRP (PT) and Beratungsstelle für Unfallverhütung - BFU $(\mathrm{CH})$ - that combined their expertise to analyse the common data and to disseminate the results. The results of the 2015 survey are published in one Main Report and in six Thematic Reports focused on the following subjects:

- $\quad$ Speeding

- Driving under the influence of alcohol and drugs

- Distraction and fatigue 
- Seat belt and child restraint systems

- Subjective safety and risk perception

- Enforcement and support for road safety policy measures

There are also 17 country fact sheets in which the main results per country are compared with a European average. An overview of the project and the results are available at

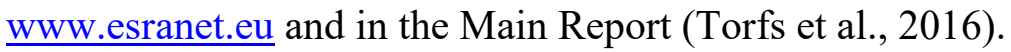

The speeding aspects analysed in the Thematic Report on Speeding (Yannis, Laiou, Theofilatos\& Dragomanovits, 2016) concern:

\section{a. Acceptability of unsafe traffic behaviour related to speeding}

This section examines the rate of acceptability of speeding related behaviours, comprising the following questions in the analysis:

Question: Where you live, how acceptable would most other people say it is for a driver to:

- drive $20 \mathrm{~km}$ per hour $(\mathrm{km} / \mathrm{h})$ over the speed limit on a motorway?

- drive $20 \mathrm{~km} / \mathrm{h}$ over the speed limit on a residential street?

- drive $20 \mathrm{~km} / \mathrm{h}$ over the speed limit in an urban area?

- $\quad$ drive $20 \mathrm{~km} / \mathrm{h}$ over the speed limit in a school zone?

- drive up to $10 \mathrm{~km} / \mathrm{h}$ above the legal speed limit?

Question: How acceptable do you, personally, feel it is for a driver to:

- drive $20 \mathrm{~km} /$ hover the speed limit on a motorway?

- drive $20 \mathrm{~km} / \mathrm{h}$ over the speed limit on a residential street?

- $\quad$ drive $20 \mathrm{~km} / \mathrm{h}$ over the speed limit in an urban area?

- drive $20 \mathrm{~km} / \mathrm{h}$ over the speed limit in a school zone?

- drive up to $10 \mathrm{~km} / \mathrm{h}$ above the legal speed limit? 
In both of the above questions, the respondents were asked to rate the acceptability levels using a 5-point scale, from 1-unacceptable to 5-acceptable. The numbers in between could be used by the respondent to refine his/her response. In the analysis, answers were dichotomized to a binary variable: acceptable (4-5) - unacceptable (1-3). The results from both questions are presented side by side in order to compare the personal acceptability with the perceived social acceptability (i.e. acceptability by 'other people').

\section{b. Self-declared (unsafe) behaviour in traffic}

In this section, the self-declared behaviour of road users with regards to speeding is investigated by presenting the answers to the following question:

Question: In the past 12 months, as a road user, how often did you:

- drive faster than the speed limit inside built-up areas?

- drive faster than the speed limit outside built-up areas (except motorways)?

- drive faster than the speed limit on motorways?

The respondents were asked to give an answer in a 5-point (Likert) scale, from 1 (never) to 5 (almost always). The numbers in between could be used by the respondent to refine his/her response. In the analysis, answers were dichotomized to a binary variable: never (1) - at least once (2-5).

\section{c. Attitudes towards unsafe traffic behaviour}

In this section, the road users' opinions on the influence of speeding on accident risk and road safety in general are investigated, through examination of the following question:

Question: To what extent do you agree with each of the following statements:

- Driving fast is risking your own life, and the lives of others?

- I have to drive fast, otherwise I have the impression of losing time? 
- Driving faster than the speed limit makes it harder to react appropriately in a dangerous situation?

- Most of my acquaintances / friends feel one should respect the speed limits?

- Speed limits are usually set at acceptable levels?

- By increasing speed by $10 \mathrm{~km} / \mathrm{h}$, you get a much higher chance of being involved in an accident?

The respondents were asked to give an answer in a 5-point (Likert) scale, from 1 (disagree) to 5 (agree). The numbers in between could be used by the respondent to refine his/her response. In the analysis answers were dichotomized to a binary variable: agree (4-5) - disagree (1-3)).

\section{d. Support for road safety policy measures}

In this section, the road users' opinions on speeding related enforcement, traffic rules and penalties is investigated. The following questions of the survey are examined:

Question: What do you think about the current traffic rules and penalties in your country for each of the following themes:

- The traffic rules (on speeding) should be stricter?

- The traffic rules (on speeding) are not being checked sufficiently?

- The penalties (for speeding) are too severe?

The respondents were asked to provide a 'yes' or 'no' response, with an additional option of 'don't know / no response'.

\section{e. Reported police checks and perceived likelihood of getting caught for traffic}

\section{offences}

In this section, police checks reported by road users and perceived likelihood of getting caught for traffic offences are investigated. The following questions of the survey are examined: 
Question: On a typical journey, how likely is it that you (as a driver) will be checked by the police for respecting the speed limits (including checks by police car with a camera and/or flash cameras)?

The respondents were asked to give an answer in a 5-point (Likert) scale, from 1 (very small chance) to 5 (very big chance). The numbers in between could be used by the respondent to refine his/her response. In the analysis answers were dichotomized to a binary variable: big chance (4-5) - small chance (1-3).

Question: In the past 12 months, how many times have you:

- $\quad$ had to pay a fine for violating the speed limit?

- been convicted at court for violating the speed limit?

In the Thematic Report on Speeding (Yannis et al, 2016) each of the listed aspects was firstly examined individually. Then, a number of aspects were selected to be cross-examined based on their expected inter-connection. Specifically, in the Thematic Report on Speeding (Yannis et al, 2016) the following combinations of speeding aspects were examined:

- Acceptability of unsafe traffic behaviour related to speeding and Support for road safety policy measures

- Acceptability of unsafe traffic behaviour related to speeding and Self-declared (unsafe) behaviour in traffic

- Acceptability of unsafe traffic behaviour related to speeding and Attitudes towards unsafe traffic behaviour

- $\quad$ Support for road safety policy measures and Perceived likelihood of getting caught for traffic offences

- $\quad$ Self-declared (unsafe) behaviour in traffic and Support for road safety policy measures 
The original data were dichotomized in order to minimize the number of answer categories in view of the analyses. More efficient estimates are obtained by combining outcome variables into binary variables. The dichotomization was done centrally and used in all analyses (Torfs et al., 2016).

Basic descriptive analyses divided by country, gender and three age groups (18-34, 35-54, 55+) was conducted. The significance tests used were T-test/ANOVA when comparing averages or a Chi-square test for the dichotomized variables. Due to the large sample size, it can be expected that most differences are significant. Therefore, by convention, a significance level of $99 \%(p=0.01)$ was used (Torfs et al., 2016).In the present paper selected analyses of the above listed individual questions or of combinations of questions are presented and the respective findings are discussed. The selection of questions to be presented was based on similar studies found in the international literature as well as on the significance of the findings. The full analysis of the speeding related questions is available in the respective Thematic Report on Speeding (Yannis et al, 2016).

This paper is based on the analysis undertaken for the development of the Thematic Report on Speeding. The method described above was also followed in the present paper.

Table 1 presents an overview of the sample. The targeted minimum number of respondents was 1,000 for each country of which at least 600 should be regular car drivers. A regular car driver was defined as a person having a car driving license and who has driven at least $1,500 \mathrm{~km}$ with a car or a van within the last 6 months. If needed, the minimum sample of 1,000 respondents could be extended in order to reach the requirement of 600 regular car drivers. The total sample size eventually consisted of 17,767 road users from 17 countries, amongst them 11,179 regular car drivers (Torfs et al., 2016).

\footnotetext{
$* * *$ Table 1 to be inserted here $* * *$
} 
The target population was the adult population (over 18 years old) of each country. The sampling variables were gender, age, and geographical distribution. However, the quota used by the market research company were based only on gender and age, while the geographical distribution within the country was monitored. Moreover, to improve quota quality, the records in the national samples were slightly corrected using small weights. For European results, a weighted European average was calculated that took into account both the representativeness within a country, as well as the proportion of the population in a specific country within the total population of the 17 participating countries (Torfs et al., 2016).

\section{Results}

Key results of both the descriptive and the cross-examination of the questions previously described are presented in the following sub-sections.

\subsection{Acceptability of unsafe traffic behaviour related to speeding}

The ESRA2015 respondents consider that perceived social acceptability is higher than the personal acceptability, indicating a self-declared safer personal attitude towards speeding. A particularly high (more than 10\%) difference between the perceived social acceptability and of personal acceptability is mostly reported in Italy and in Greece. Similar results were found in the previous SARTRE surveys. Italy and Poland are the two countries that - show higher acceptability rates of behaviours related to speeding than the European average, both regarding social perceived acceptability and personal acceptability.

Acceptability of behaviours related to speeding can be divided into two groups: there is minor acceptability of driving $20 \mathrm{~km} / \mathrm{h}$ over the speed limit in urban areas, on residential streets and in school zones. On the other hand, acceptability of driving $20 \mathrm{~km} / \mathrm{h}$ over the 
speed limit on a motorway and acceptability of driving up to $10 \mathrm{~km} / \mathrm{h}$ over the speed limit, regardless of the road environment, is much higher (Figure 1).

\section{*** Figure 1 to be inserted here ***}

Analysing the reported acceptability of speeding behaviours by gender reveals that acceptability rates are lower amongst females comparing to males, for all five examined speeding related behaviours, both regarding perceived social acceptability and personal acceptability.

Age also affects acceptability rates. Age increase is associated with a decrease in acceptability rates for all five examined speeding related behaviours (driving $20 \mathrm{~km} / \mathrm{h}$ over the speed limit on motorways, on residential streets, in urban areas, in school zones and driving up to $10 \mathrm{~km} / \mathrm{h}$ above the legal speed limit). Furthermore, this decrease in acceptability rates is observed both at the personal level and the 'other people' level.

\subsection{Self-declared unsafe traffic behaviour related to speeding}

More than two-thirds of the respondents reported having driven faster than the speed limit at least once in the past 12 months, for all the examined cases. The analysis by gender shows that all the reported behaviours related to speeding depend on the gender with more males than females declaring that they have driven faster than the speed limit (Figure 2). Speeding also depends on age. Age increase is generally associated with a decrease in the tendency to violate the speed limit; an exception is observed in the case of motorways, where the greatest percentage of having driven faster than the speed limit at least once in the past 12 months is reported by those in the 35-54 years old group (Figure 3).

\footnotetext{
$* * *$ Figure 2 to be inserted here $* * *$

$* * *$ Figure 3 to be inserted here $* * *$
} 


\subsection{Attitudes towards unsafe traffic behaviour}

The majority of the respondents agree that 'driving fast is risking your own life, and the lives of others' and that 'driving faster than the speed limit makes it harder to react appropriately in a dangerous situation' which shows that the consequences of speeding are quite clear to them. However, only half of them agree that speed limits are usually set on acceptable levels indicating a low trust to the enforcement rules.

The analysis by gender shows that females are generally more aware of the influence of speeding on road safety. Similarly, respondents of 55 years old and older are more aware of the influence of speeding on road safety than responders in the 35-54 year old age group, who in turn are more aware than the 18-34 year old age group.

\subsection{Support for road safety policy measures}

Approximately half of the respondents agree that in their country traffic rules should be stricter and that traffic rules are not being checked sufficiently. However, more than one third believe that penalties for speeding in their country are too severe.

The significant differences among European countries could be explained based on the different cultural and social background of the respondents from various countries as well as the different legislation and enforcement systems (Table 2).

$* * *$ Table 2 to be inserted here $* * *$

The analysis by gender and by age shows that females and older people (55+) are generally more supportive of strict traffic rules, efficient enforcement and severe penalties for speeding.

\subsection{Perceived likelihood of getting caught for traffic offences}


At the European level, a $36 \%$ of respondents consider it likely to be checked by the police for respecting the speed limits (including checks by police car with a camera and/or flash cameras) on a typical journey. This percentage differs between the countries (Figure 4).

$* * *$ Figure 4 to be inserted here $* * *$

\subsection{Cross-examination of acceptability of unsafe traffic behaviour related to speeding and support for road safety policy measures}

The cross-examination of the acceptability of unsafe traffic behaviours related to speeding and the support for relevant traffic rules and penalties shows a general coherence in the answers to the two questions.

The percentage of respondents who find driving over the speed limit acceptable and also think that the traffic rules for speeding should be stricter reaches only $27 \%$ and $29 \%$ respectively in the case of motorways and for an increase of $10 \mathrm{~km} / \mathrm{h}$ over the speed limit. However, this percentage is increased to $39 \%$ and $38 \%$ respectively in the case of residential streets and urban areas and 50\% in the case of school zones (Figure 5). The same trend is observed regarding the sufficient enforcement of traffic rules for speeding.

$* * *$ Figure 5 to be inserted here ***

Penalties for speeding are considered too severe by more than $50 \%$ of those who find driving over the speed limit acceptable. This is the case for all the examined different road types.

3.7 Cross-examination of self-declared unsafe traffic behaviour related to speeding and acceptability of unsafe traffic behaviour related to speeding 
The examination of the self-declared behaviour and acceptability of unsafe traffic behaviour related to speeding revealed a significant inconsistence between practice (selfdeclared behaviour) and theory (acceptability of unsafe behaviour). Specifically, those who consider driving over the speed limit unacceptable, admitted having done so at least once during the last 12 months in a percentage that ranges from $60 \%$ to $72 \%$ (Table 3 ).

$* * *$ Table 3 to be inserted here $* * *$

\subsection{Cross-examination of acceptability of unsafe traffic behaviour related to speeding and attitudes towards unsafe traffic behaviour related to speeding}

An expected finding is that the majority of people who accept driving over the speed limit do not believe that the speed limits are set at acceptable levels. One fourth to one third of the people who consider driving over the speed limit on motorways $(25 \%)$, residential street $(35 \%)$ and in urban areas (34\%) acceptable, also accept that this increases the risk of being involved in an accident. The specific percentage reaches $42 \%$ when driving in school zones is considered. This indicates that these people are willing to take this increased risk. However, they also realise the increased hazards in a school zone.

Similar findings are observed when the difficulty to react appropriately in dangerous situations caused by driving over the speed limit is examined and when the risk for life is examined.

\subsection{Cross-examination of support for road safety policy measures and perceived}

\section{likelihood of getting caught for traffic offences}

Only one third of the respondents who find that traffic rules should be stricter and that they are not being checked sufficiently, also agree that there is a (very) big chance to be 
checked by the police for respecting the speed limits on a typical journey. These findings are logical and indicate a coherence between the answers to the two questions.

On the other hand, a bit less than half (45\%) of those considering penalties for speeding too severe, also agree that there is a (very) big chance to be checked by the police for respecting the speed limits on a typical journey. This might indicate a general belief of an existing strict speed enforcement system (Figure 6).

\section{$* * *$ Figure 6 to be inserted here $* * *$}

\section{Discussion}

Speed is a key road safety issue as it has been found to be a major contributory factor in around $10 \%$ of all accidents and in around $30 \%$ of the fatal accidents. Both excess speed (exceeding the posted speed limit) and inappropriate speed (faster than the prevailing conditions allow) are important accident causation factors (European Commission, 2018).

Generally, many drivers exceed the posted speed limits. This is the case for all road types based on both objective observations and self-reported speed behaviour. All speeding related attitudes reported within ESRA2015 depend on the gender of the driver with more males than females declaring that they have driven faster than the speed limit. Age increase is generally associated with a decrease in the tendency to violate the speed limit.

ESRA2015 findings on acceptability of behaviours imply an increased sensitivity towards the violation of speed limits in areas with increased pedestrian traffic and may be attributed to the recognition of the increased risk for pedestrians due to speed. However, it must also be taken into account that driving $20 \mathrm{~km} / \mathrm{h}$ over the speed limit on motorways may happen even unintentionally or without realising it due to the high speeds developed on this type of roads. Similarly, driving up to $10 \mathrm{~km} / \mathrm{h}$ over the speed limit can accidentally happen on all types of roads and areas. 
One fourth to one third of the people who consider driving over the speed limit on motorways, residential streets and in urban areas acceptable, also accept that this increases the risk of being involved in an accident. The specific percentage reaches $42 \%$ when driving in school zones is considered. This indicates that these people are willing to take this increased risk. However, they also realise the increased hazards in a school zone.

The cross-examination of the acceptability of unsafe traffic behaviours related to speeding and the support for relevant traffic rules and penalties shows that the majority of people who accept driving over the speed limit do not believe that the speed limits are set at acceptable levels. However, even people who accept driving over the speed limit, are in favour of enforcement measures to increase road safety in urban areas and especially in school zones. This may be considered another indication of recognising the increased risk for pedestrians due to speed as well as of an increased sensitivity towards the safety of children. Speeding aspects for which significant differences among countries were recorded, include the acceptability of unsafe traffic behaviours, opinions concerning traffic rules and penalties and probability to be checked. This implies that strategies to address these issues should be defined according to the local conditions.

Some of the ESRA2015 questions are identical or highly similar to questions used in SARTRE4 (Cestac \& Delhomme, 2012 - data collection organized in 2010) and 13 countries participated in both projects. This allow an assessment of the evolution of certain topics. However, it remains challenging to assess whether the observed differences between ESRA2015 and SARTRE4 reflect real evolutions or whether these are induced by the differences in methodologies used in ESRA2015 (online survey) and SARTRE4 (face-to-face interviews) (Torfs et al, 2016). According to several studies, socially desirable responding is more likely to occur in interviewer-administered surveys than in web surveys when studying sensitive topics such as one's speeding behaviour (Baker et al., 2010; specifically in the 
SARTRE-context: Goldenbeld \& de Craen, 2013). Unfortunately, the ESRA2015 questionnaire did not include a social desirability scale. Thus, caution is needed when interpreting the results. All in all, the results indicated that online respondents were less inclined to give socially desirable answers, confirming earlier research.

SARTRE4 has also found that drivers in Europe have a relatively positive attitude towards speeding, although this tends to be most common among young drivers and men. In general, they were found to believe that speeding is rather widespread among other drivers, especially outside built up areas. This would then imply that speeding is regarded as a fairly normal behaviour. The attitude towards speed enforcement and speed reduction tended to be rather negative, although a fairly large proportion would not object to punishments becoming more severe. Some changes over time had taken place and in some countries the perceived risk of being stopped by the police had increased, and perhaps as a consequence of this, the percentage who had been fined had also increased.

Similar to the results of SARTRE4, the ESRA2015 results show that acceptability of driving $20 \mathrm{~km} / \mathrm{h}$ over the speed limit on a motorway and acceptability of driving up to 10 $\mathrm{km} / \mathrm{h}$ over the speed limit, regardless of the road environment, is much higher than acceptability of speeding in school zones or urban areas.

The ESRA2015 survey was also partially based on the 'Traffic Safety Culture Index'survey of the AAA Foundation for Traffic Safety (USA) which is an American foundation that aims to understand - and strengthen - a culture of safety on roads in the USA by measuring and benchmarking the attitudes and behaviours of American drivers using their Traffic Safety Culture Index (TSCI) (AAAFTS, 2016). The TSCI is also an online questionnaire, in which the following themes are covered: threats on the highway, acceptability of behaviours, support for laws and countermeasures, and frequency of engaging in risky behaviours. Although there are common objectives and similar topics 
covered in ESRA2015 and TSCI, the questionnaires are too dissimilar for a full comparison. Nonetheless, a tentative comparison on the safety attitudes of Europeans and Americans is possible, and two questions are suited for this comparison: the personal acceptability and the perceived social acceptability of unsafe traffic behaviour. Six items are identical and the answering scales are very similar in both questionnaires (Torfs et al, 2016).

The results show that for the items covered the perceived social acceptability in general is higher in the USA than in Europe. The largest discrepancies are observed for distracted driving. The pattern is less clear when personal acceptability is considered. Nevertheless, acceptability of drink-driving is lowest compared to speeding and distracted driving. The differences in acceptability of speeding could be explained by the slight differences in the actual violations asked. For example, the speed violation in urban areas in TSCI was somewhat lower than in ESRA2015 (respectively, 16 and $20 \mathrm{~km} / \mathrm{h}$ ), consequently, personal acceptability was higher in the USA.

A characteristic of the ESRA2015 survey was the fact that a regular car driver was defined as a person having a car driving license and who had driven at least $1,500 \mathrm{~km}$ with a car or a van within the last 6 months. However, no further details on the distribution of these 1,500 $\mathrm{km}$ along the 6 month period were collected. This means that some non-regular drivers who had completed few long journeys during the examined period may have also been included in the sample. To eliminate this chance it is suggested that in future versions of the ESRA2015 survey the definition of a regular driver also includes a measure of the regularity of driving within a selected period.

Another issue that can be examined in future analysis is the different attitudes of professional and non-professional drivers towards speeding, especially in different situations (inside/ outside urban areas, on different types of roads, in specific areas such as school areas, during worktime or not etc). Furthermore, attitudes towards speeding as reported within 
ESRA could be compared to real-world behaviour data and enforcement outcomes and provide more insight of the difference between self-declared and measured behaviour.

\section{Recommendations}

The findings of the ESRA2015 survey on speeding in combination with the overall results of the survey on road users' safety attitudes and based on the wider knowledge of the road safety issues has led the ESRA2015 project to be concluded with the formulation of a series of relevant recommendations. In order to contribute to the apparent need for action by different stakeholders, also adjusted to the local conditions to reduce the problem of speeding, recommendations in relation to speeding were formulated at three different levels of authority namely policy recommendations at European level, specific policy recommendations at national and regional level and specific recommendations to particular stakeholders such as non-governmental organizations, private concessionaire companies, research organisations and vehicle manufacturers. The complete list of ESRA recommendations concerning speeding are presented in Yannis et al (2016). Below, recommendations that are most relevant to the results and findings presented in this paper are listed.

$\underline{\text { Policy recommendations at European level: }}$

- Develop common principles and goals for speed management strategies in the Member States as part of European Union directives and other legislative procedures.

- Define speed related indicators and set targets at European Union level, such as the number of speed checks, the number of speeders and the number of traffic casualties attributable to speed.

Specific policy recommendations at national and regional level 
- Establish a speed management strategy that is based on integrated set of countermeasures, such as setting speed limits, providing information about the speed limit in force, implementing road engineering measures, enforcing speed limits, ensuring appropriate driver education and informing the public of the negative impact of speeding.

- Select the most appropriate combination of speeding measures based on an assessment of the local circumstances.

- Develop an efficient speed enforcement system that includes a careful selection of location and duration of control activities, user awareness of speed enforcement activities, systematic recording of speed controls and infringements and public communication of the results of speed enforcement activities.

\section{$\underline{\text { Specific recommendations to particular stakeholders }}$}

- [To research organisations] Contribute to the development, monitoring and evaluation of the implementation of speed management strategies.

\section{Acknowledgment}

This research was carried out within the ESRA project (European Survey of Road users' safety Attitudes), a joint initiative of research organisations and road safety institutes in 17 European countries. The project was funded by the partners' own resources and coordinated by VIAS Institute.

\section{References}


AAA Foundation for Traffic Safety (2016). 2015 Traffic Safety Culture Index. Washington, DC: AAA Foundation for Traffic Safety. Retrieved from https://www.aaafoundation.org/sites/default/files/2015_TSCI.pdf[25.05.16]

Baker, R., Blumberg, S. J., Brick, J. M., Couper, M. P., Courtright, M., Dennis, J. M., et al. (2010). AAPOR Report on online panels. Public Opinion quarterly, 74(4), 711781.

Cestac, J. \& Delhomme P. (2012). European road users' risk perception and mobility. The SARTRE 4 survey: Public Imprim.

Elvik, R. (2013). A re-parameterisation of the Power Model of the relationship between the speed of traffic and the number of accidents and accident victims. Accident Analysis and Prevention, Vol.50, pp.854-860.

Elvik, R. (2009). The Power Model of the relationship between speed and road safety: update and new analyses. ТØI Report 1034/2009, Institute of Transport Economics TØI, Oslo.

Elvik, R., Christensen P. and Amundsen A.(2004). Speed and road accidents; An evaluation of the Power Model. Institute of Transport Economics TØI.

ETSC (2010). Tackling the three main killers on the roads. A priority for the forthcoming EU Road Safety Action Programme. PIN Flash n.16: European Transport Safety Council. Brussels, Belgium.

European Commission. (2018). Speed and Speed Management. European Commission, Directorate General for Transport. Brussels, Belgium.

European Commission, COM. (2010) 389 final, 20.7.2010, Brussels, Belgium.

Fleiter, J.J. \& Watson, B.C. (2006) The speed paradox : the misalignment between driver attitudes and speeding behaviour. Journal of the Australasian College of Road Safety, 17(2), pp. 23-30. 
Goldenbeld, C., \& de Craen, S. (2013). The comparison of road safety survey answers between web-panel and face-to-face; Dutch results of SARTRE-4 survey. Journal of Safety Research, 46, 13-20.

Hatfield J. \&Job R.F.S. (2006). Beliefs and Attitudes about Speeding and its Countermeasures. Australian Transport Safety Bureau (ATSB) Research and Analysis Report, Road Safety Research Grant B2001/0342, Sydney, Australia.

Laiou A., Yannis G. and Možina K. (2015). A Speed Management Strategy for the Peloponnese. Proceedings of the 6th Pan-hellenic Road Safety Conference, Hellenic Institute of Transportation Engineers, National Technical University of Athens, Athens.

Lawton R., Parker D., Stradling S.G. (1997).Self-reported attitude towards speeding and its possible consequences in five different road contexts. Journal of Community \& Applied Social Psychology, Vol. 7, pp.153-165.

Nilsson, G. (1981). The effects of speed limits on traffic accidents in Sweden. In: Proceedings of the international symposium on the effects of speed limits on traffic accidents and transport energy use, 6-8 October 1981, Dublin. OECD, Paris, p. 1-8.

Nilsson, G. (2004). Traffic safety dimensions and the power model to describe the effect of speed on safety. Lund Bulletin 221. Lund Institute of Technology, Lund.

OECD/ECMT (2006). Speed Management. Organisation for Economic Co-Operation and Development (OECD), European Conference of Ministers of Transport (ECMT). Paris, France.

OECD/ITF (2018). Speed and Crash Risk. Organisation for Economic Co-Operation and Development (OECD), International Transport Forum (ITF). Paris, France. 
Schroeder, P., Kostyniuk, L., Mack, M. (2013). 2011 National Survey of Speeding Attitudes and Behaviors. (Report No. DOT HS 811 865). Washington, DC: National Highway Traffic Safety Administration.

Stephens, A.N., Nieuwesteeg M., Page-Smith J., Fitzharris M. (2017) Self-reported speed compliance and attitudes towards speeding in a representative sample of drivers in Australia. Accident Analysis and Prevention 103, pp.56-64.

SWOV (2012) SWOV Fact Sheet - The relation between speed and crashes. Retrieved from: http://www.swov.nl/rapport/Factsheets/UK/FS_Speed.pdf [16.02.15]

Torfs, K., Meesmann U., Van den Berghe W. and Trotta M. (2016). ESRA 2015 - The results. Synthesis of the main findings from the ESRA survey in 17 countries. ESRA project (European Survey of Road users' safety Attitudes). Brussels, Belgium: Belgian Road Safety Institute.

Yannis, G., Laiou A., Theofilatos A. and Dragomanovits A. (2016). Speeding. ESRA thematic report no. 1. ESRA project (European Survey of Road users' safety Attitude). Athens, Greece: National Technical University of Athens.

Wegman, F. and Aarts L. (2006). Advancing sustainable safety. National Road Safety Outlook for 2005-2020. SWOV, Leidschendam. 
Table 1. Specifications of the sample by country(unweighted sample)

\begin{tabular}{|c|c|c|c|c|c|c|c|}
\hline & \multicolumn{2}{|c|}{ Sample size } & \multicolumn{2}{|c|}{ Gender } & \multicolumn{3}{|c|}{ Age group } \\
\hline & total & $\begin{array}{c}\text { regular car } \\
\text { drivers }\end{array}$ & male & female & $18-34$ & $35-54$ & $55+$ \\
\hline Austria & 1,019 & 699 & $50 \%$ & $50 \%$ & $26 \%$ & $43 \%$ & $31 \%$ \\
\hline Belgium & 1,000 & 630 & $49 \%$ & $51 \%$ & $25 \%$ & $39 \%$ & $36 \%$ \\
\hline Switzerland & 1,000 & 604 & $52 \%$ & $48 \%$ & $27 \%$ & $39 \%$ & $34 \%$ \\
\hline Germany & 1,000 & 665 & $52 \%$ & $48 \%$ & $26 \%$ & $38 \%$ & $36 \%$ \\
\hline Denmark & 1,077 & 821 & $55 \%$ & $45 \%$ & $20 \%$ & $36 \%$ & $44 \%$ \\
\hline Greece & 1,113 & 610 & $43 \%$ & $57 \%$ & $26 \%$ & $55 \%$ & $18 \%$ \\
\hline Spain & 1,021 & 632 & $49 \%$ & $51 \%$ & $40 \%$ & $48 \%$ & $12 \%$ \\
\hline Finland & 1,016 & 742 & $53 \%$ & $47 \%$ & $25 \%$ & $34 \%$ & $41 \%$ \\
\hline France & 1,001 & 698 & $49 \%$ & $51 \%$ & $31 \%$ & $41 \%$ & $29 \%$ \\
\hline Ireland & 1,000 & 610 & $52 \%$ & $48 \%$ & $33 \%$ & $45 \%$ & $22 \%$ \\
\hline Italy & 838 & 593 & $56 \%$ & $44 \%$ & $41 \%$ & $40 \%$ & $19 \%$ \\
\hline Netherlands & 1,106 & 662 & $46 \%$ & $54 \%$ & $32 \%$ & $44 \%$ & $24 \%$ \\
\hline Poland & 1,085 & 601 & $52 \%$ & $48 \%$ & $38 \%$ & $38 \%$ & $24 \%$ \\
\hline Portugal & 1,028 & 712 & $51 \%$ & $49 \%$ & $31 \%$ & $54 \%$ & $15 \%$ \\
\hline Sweden & 1,298 & 595 & $44 \%$ & $56 \%$ & $25 \%$ & $34 \%$ & $40 \%$ \\
\hline Slovenia & 1,002 & 699 & $51 \%$ & $49 \%$ & $33 \%$ & $41 \%$ & $26 \%$ \\
\hline Un.Kingdom & 1,163 & 606 & $49 \%$ & $51 \%$ & $30 \%$ & $42 \%$ & $27 \%$ \\
\hline
\end{tabular}

Note: Italy used different sampling methods. Only online sampling has been taken into account in this overview. 
Table 2. Support for road safety policy measures related to speeding, by country (\% of agreement: scores 4 and 5 on a 5-point scale from 1 'disagree' to 5 'agree').

\begin{tabular}{|c|c|c|c|}
\hline & $\begin{array}{l}\text { the traffic rules (for speeding) } \\
\text { should be stricter }\end{array}$ & $\begin{array}{c}\text { the traffic rules (for speeding) are } \\
\text { not being checked sufficiently }\end{array}$ & $\begin{array}{l}\text { the penalties (for speeding) are } \\
\text { too severe }\end{array}$ \\
\hline Austria & $33 \%$ & $42 \%$ & $44 \%$ \\
\hline Belgium & $45 \%$ & $51 \%$ & $33 \%$ \\
\hline Switzerland & $34 \%$ & $35 \%$ & $43 \%$ \\
\hline Germany & $42 \%$ & $49 \%$ & $28 \%$ \\
\hline Denmark & $27 \%$ & $57 \%$ & $27 \%$ \\
\hline Greece & $83 \%$ & $80 \%$ & $35 \%$ \\
\hline Spain & $52 \%$ & $52 \%$ & $51 \%$ \\
\hline Finland & $49 \%$ & $56 \%$ & $30 \%$ \\
\hline France & $43 \%$ & $45 \%$ & $53 \%$ \\
\hline Ireland & $62 \%$ & $62 \%$ & $30 \%$ \\
\hline Italy & $59 \%$ & $58 \%$ & $29 \%$ \\
\hline Netherlands & $37 \%$ & $37 \%$ & $54 \%$ \\
\hline Poland & $72 \%$ & $66 \%$ & $29 \%$ \\
\hline Portugal & $52 \%$ & $55 \%$ & $51 \%$ \\
\hline Sweden & $44 \%$ & $60 \%$ & $28 \%$ \\
\hline Slovenia & $47 \%$ & $53 \%$ & $58 \%$ \\
\hline Un.Kingdom & $60 \%$ & $62 \%$ & $28 \%$ \\
\hline EU & $52 \%$ & $54 \%$ & $37 \%$ \\
\hline
\end{tabular}

Note: The highest percentages are highlighted in light grey and the lowest in dark grey 
Table 3: Responses combining acceptability of unsafe traffic behaviour related to speeding (1) and adopted attitudes as a road user in the past 12 months, related to speeding, in Europe

(Grouped scores 1 to 3 '(rather) unacceptable / neutral' and 4 to 5 '(rather) acceptable)' on a 5-point scale from 1 'unacceptable' to 5 'acceptable'. Responses combining non-acceptability of driving over the speed limit and admitting having adopted the specific behaviour at least once in the past 12 months are indicated in grey).

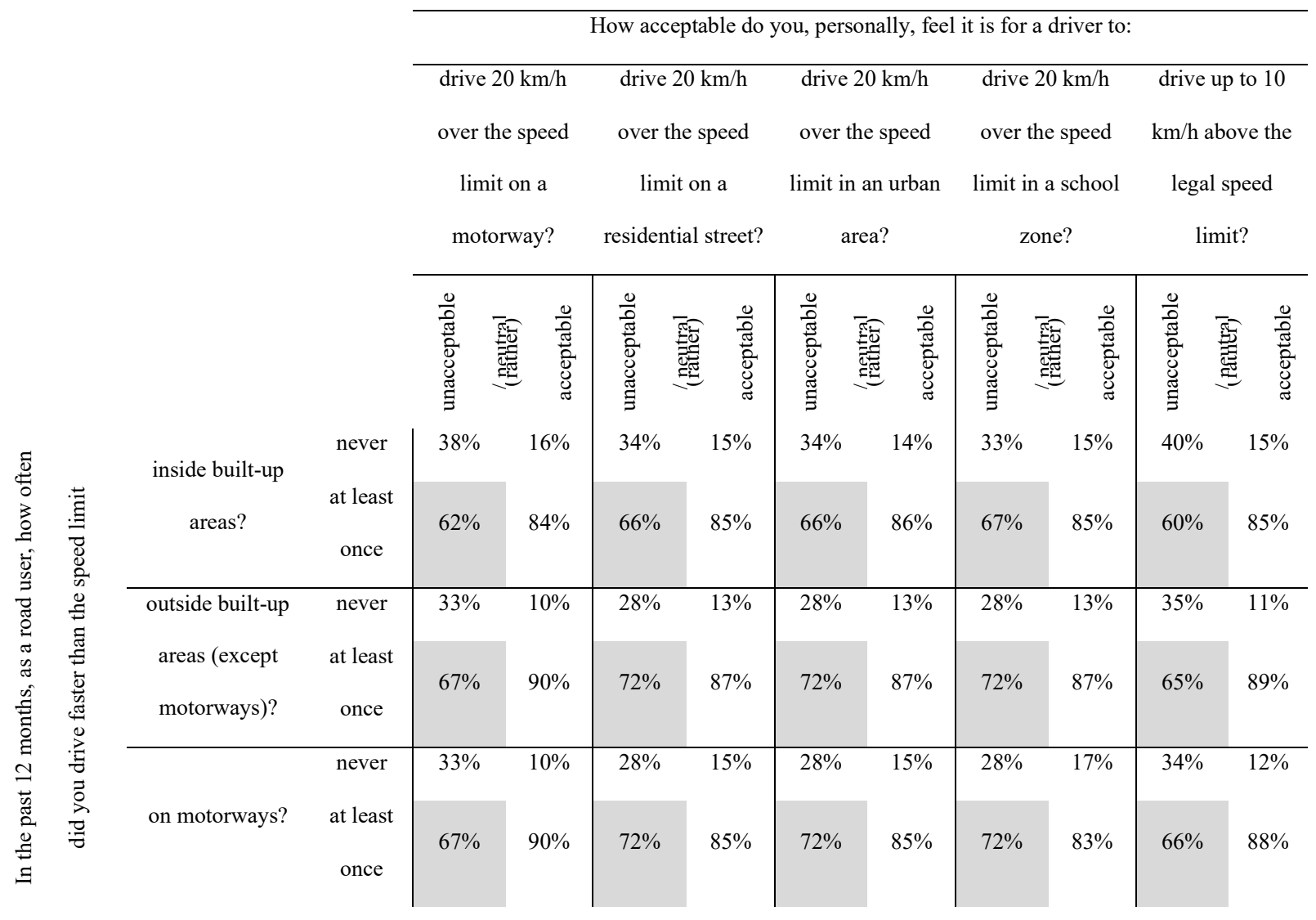


drive $20 \mathrm{~km} / \mathrm{h}$ over the speed limit on a motorway

drive $20 \mathrm{~km} / \mathrm{h}$ over the speed limit on a residential street

drive $20 \mathrm{~km} / \mathrm{h}$ over the speed limit in an urban area

drive $20 \mathrm{~km} / \mathrm{h}$ over the speed limit in a school zone

drive up to $10 \mathrm{~km} / \mathrm{h}$ above the legal speed limit

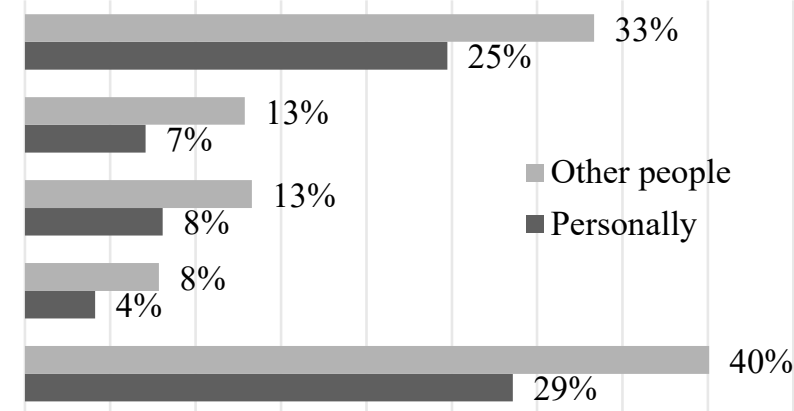

$\begin{array}{llllllllll}0 \% & 5 \% & 10 \% & 15 \% & 20 \% & 25 \% & 30 \% & 35 \% & 40 \% & 45 \%\end{array}$

$\%$ of acceptance

Figure 1. Acceptability of unsafe traffic behaviour related to speeding, in Europe

(\% of acceptability: scores 4 and 5 on a 5-point scale from 1 'unacceptable' to 5 'acceptable'). 


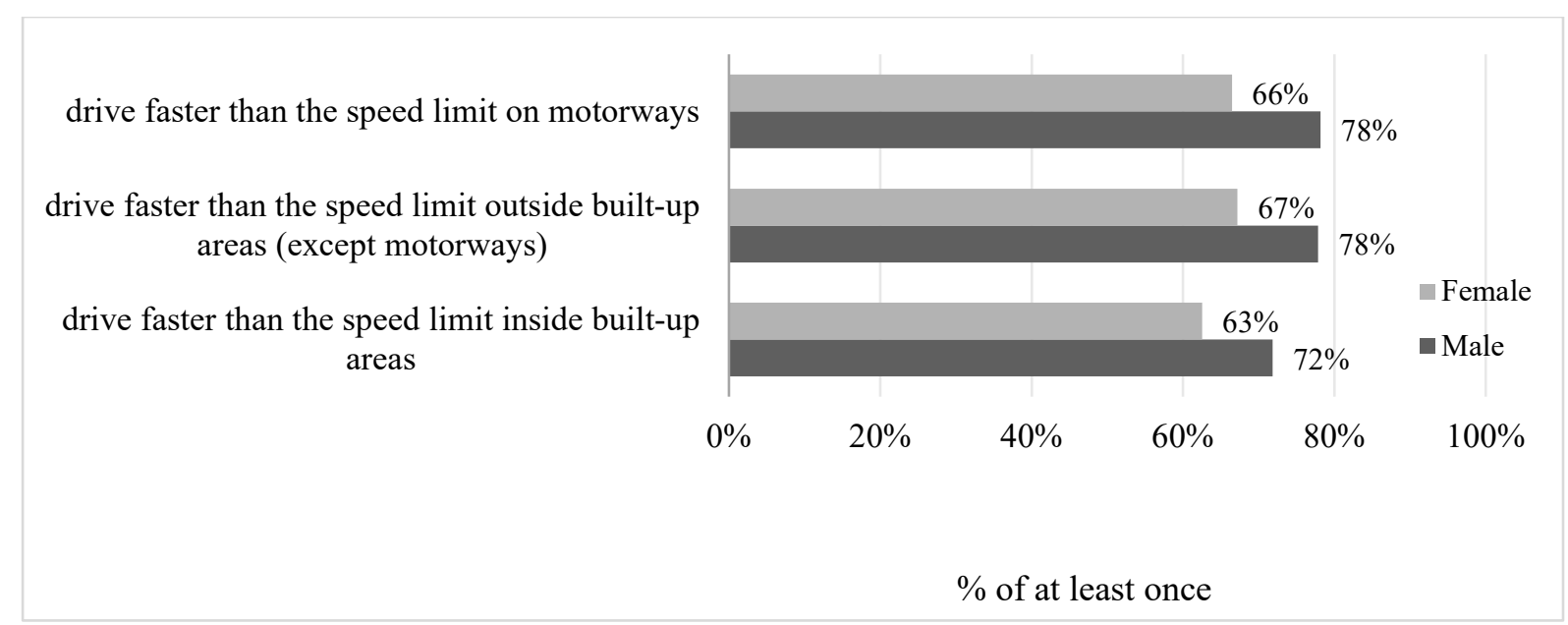

Figure 2. Self-declared speeding in the past 12 months, by gender

(\% of people that did it at least once in the past 12 months). 


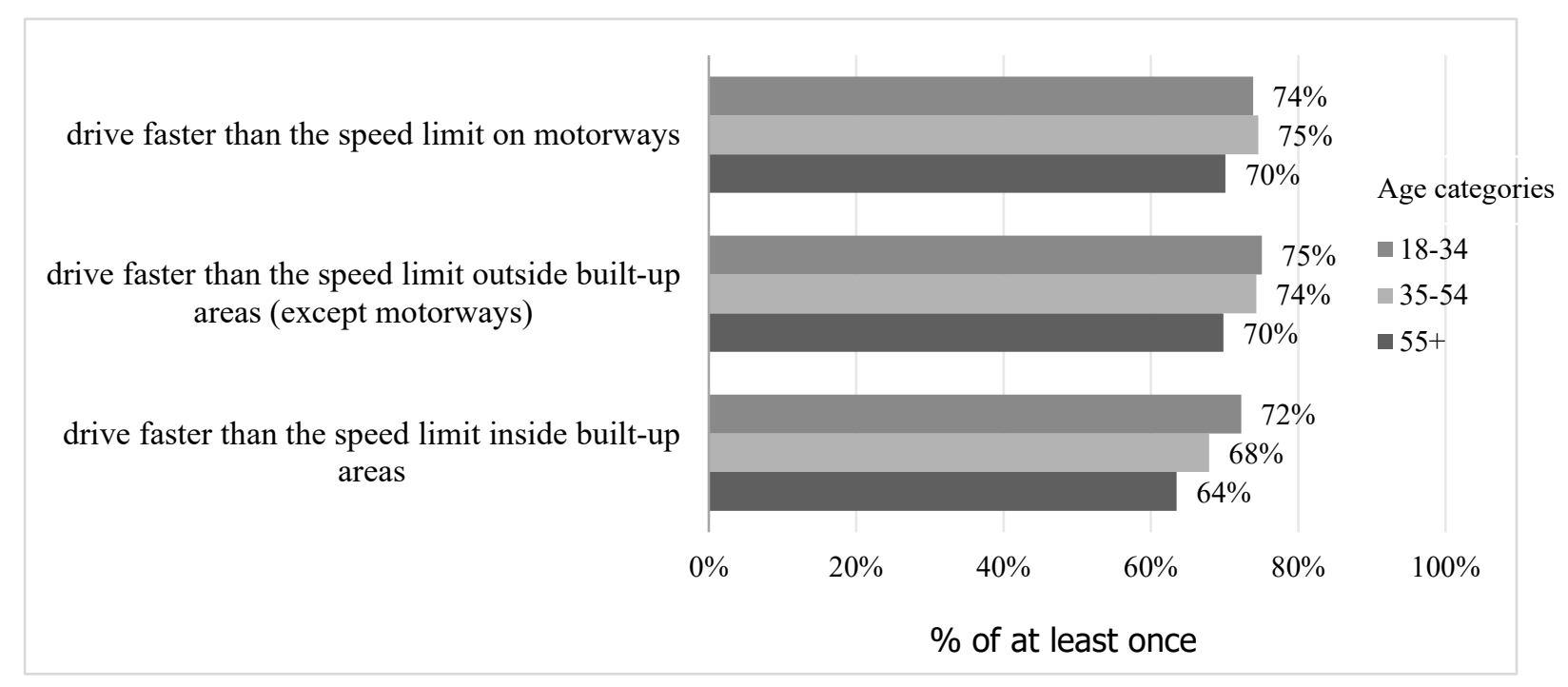

Figure 3. Self-declared speeding in the past 12 months, by age group

(\% of people that did it at least once in the past 12 months). 


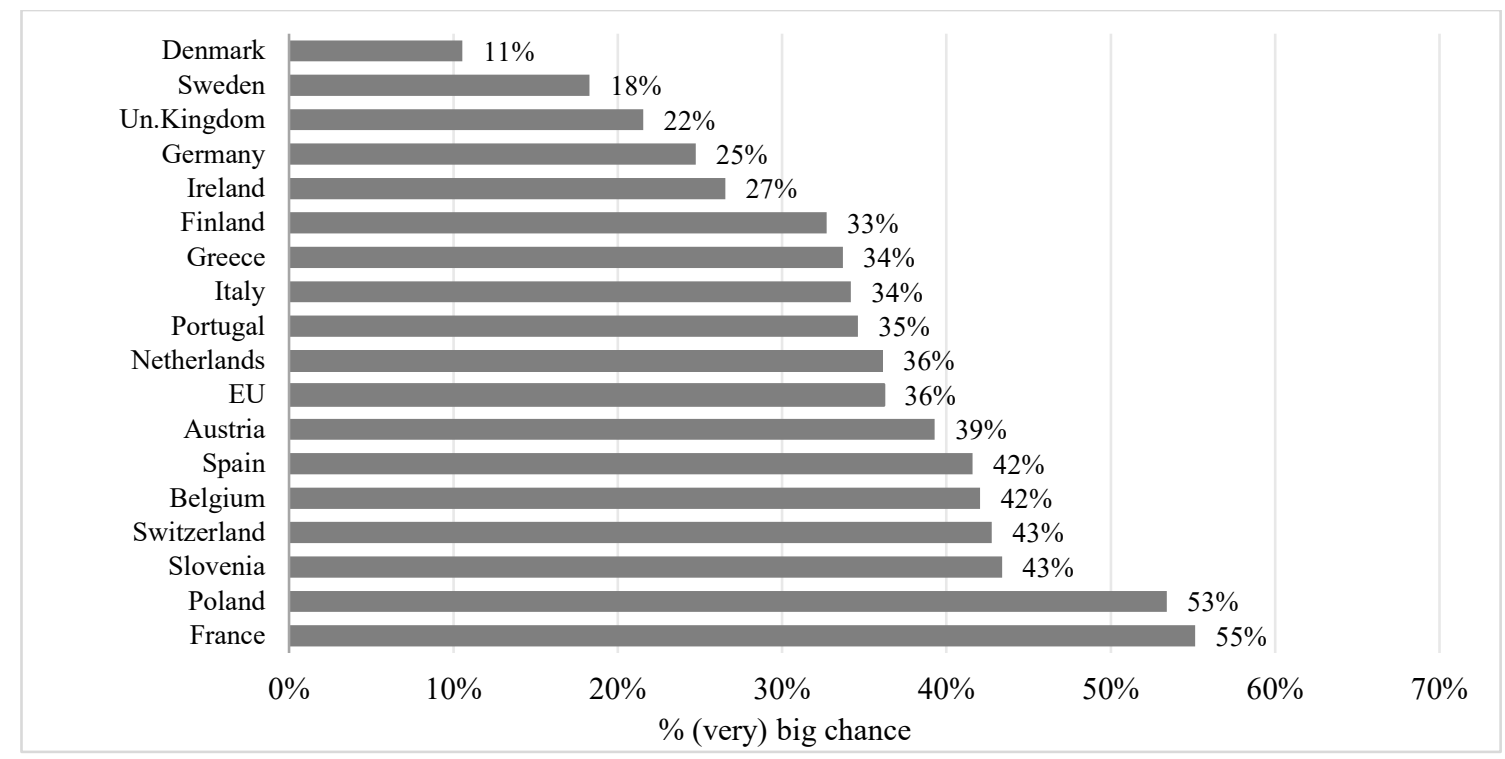

Figure 4: Perceived likelihood of being checked by the police for respecting the speed limits, by country ( $\%$ of (very) big chance; scores 4 and 5 on a 5 -point scale from 1 'very small chance' to 5 'very big chance'). 
drive $20 \mathrm{~km} / \mathrm{h}$ over the speed limit on a motorway is acceptable

drive $20 \mathrm{~km} / \mathrm{h}$ over the speed limit on a residential street is acceptable

drive $20 \mathrm{~km} / \mathrm{h}$ over the speed limit in an urban area is acceptable

drive $20 \mathrm{~km} / \mathrm{h}$ over the speed limit in a school zone is acceptable

drive up to $10 \mathrm{~km} / \mathrm{h}$ above the legal speed limit is acceptable

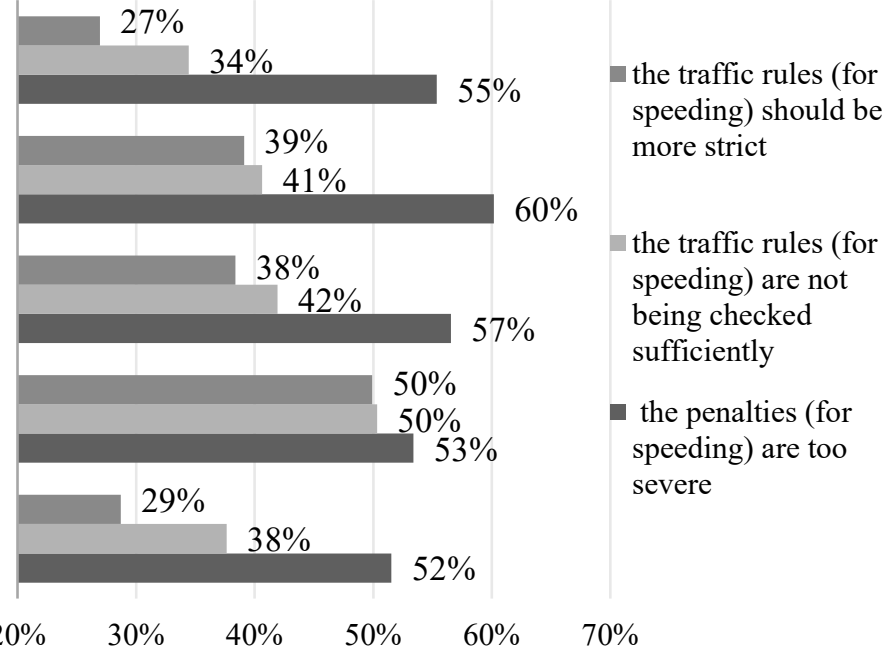

$\%$ of agreement

Figure 5: Responses combining acceptability of unsafe traffic behaviour related to speeding (1) and support for road safety policy measures related to speeding (2), in Europe

(Scores 4 and 5 on a 5-point scale from 1 'unacceptable' to 5 'acceptable', $\%$ of agreement: scores 4 and 5 on a 5 -point scale from 1 'disagree' to 5 'agree'). 
The traffic rules (for speeding) should be more strict

The traffic rules (for speeding) are not being checked sufficiently

The penalties (for speeding) are too severe

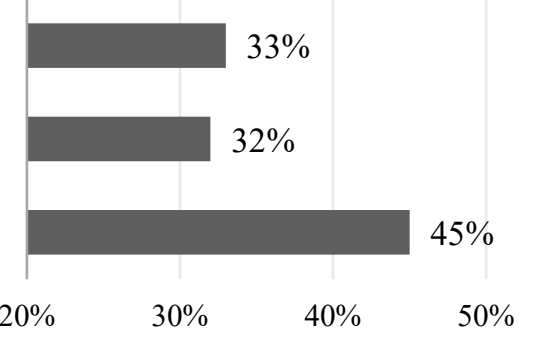

- (very) big chance to be checked (as a driver) by the police for respecting the speed limits on a typical journey (including checks by police car with a camera and/or flash cameras)

$\%$ of agreement

Figure 6: Responses combining positive support for road safety policy measures related to speeding and an increased likelihood of being checked by the police for respecting the speed limits, in Europe

( $\%$ of agreement: scores 4 and 5 on a 5 -point scale from 1 'disagree' to 5 'agree'). 